\title{
On the Viscoelastic Parameters of Gussasphalt Mixture Based on Modified Burgers Model: Deviation and Experimental Verification
}

\author{
Faxiang Xie, ${ }^{1}$ Dengjing Zhang, ${ }^{2}$ Ao Zhou, ${ }^{1}$ Bohai Ji, ${ }^{1}$ and Lin Chen ${ }^{1}$ \\ ${ }^{1}$ College of Civil and Transportation Engineering, Hohai University, Nanjing 210098, China \\ ${ }^{2}$ Nanjing Public Infrastructure Construction Center, Nanjing 210098, China \\ Correspondence should be addressed to Faxiang Xie; xiefaxiang@gmail.com
}

Received 11 November 2016; Revised 13 February 2017; Accepted 16 February 2017; Published 7 March 2017

Academic Editor: Meor O. Hamzah

Copyright (C) 2017 Faxiang Xie et al. This is an open access article distributed under the Creative Commons Attribution License, which permits unrestricted use, distribution, and reproduction in any medium, provided the original work is properly cited.

\begin{abstract}
Viscoelasticity is an important characteristic of gussasphalt mixtures. The aim of this study is to find the correct viscoelastic material parameters of the novel gussasphalt applied in the 4th Yangtze River Bridge based on the modified Burgers model. This study firstly derives the explicit Prony series form of the shear relaxation modulus of viscoelastic material from Laplace transformation, to fulfill the parameter inputting requirements of commonly used finite element software suites. Secondly, a kind of uniaxial penetration creep experiment on the gussasphalt mixtures is conducted. By fitting the creep compliance, the viscoelastic parameters characterized by the modified Burgers model are obtained. And thirdly, based on the viscoelastic test data of asphalt mixtures, the Prony series formula derived in this study is verified through the finite element simulation. The comparison results of the relative errors between the finite element simulation and the theoretical calculation confirm the reliability of the Prony series formulas deduced in this research. And finally, a stress-correcting method is proposed, which can significantly improve the accuracy of model parameters identification and reduce the relative error between the finite element simulation and the experimental data.
\end{abstract}

\section{Introduction}

Due to many eminent advantages, asphalt pavements have become the main structural form of Chinese highway. As a kind of viscoelastic material, asphalt mixtures produce viscous flows while bearing heavy loads at high temperature, thus producing nonrecoverable residual deformations [1]. With increasingly growing axle loads, rutting has become one of the most serious types of damage of asphalt pavements. Therefore, it is of great importance for the pavement engineers to describe the viscoelastic properties of asphalt mixtures while predicting rut formation and depth $[2,3]$. Meanwhile, the new formulation of gussasphalt mixture and novel structural layer has been adopted in the construction of the 4th Nanjing Yangtze River Bridge which is 6th largest suspension bridge in the world [4]. However, to the best of the authors' knowledge, the viscoelastic properties of the novel asphalt pavement which could be used to predict the ruts have never been measured, which has motivated research.
Much research has investigated viscoelastic models of asphalt mixtures, such as the generalized model, rheological model, and master curve model. Among these models, the rheological Burgers model is extensively mentioned for their convenience in practical applications. $\mathrm{Xu}$ and $\mathrm{Zhu}$ [5] proposed the modified Burgers model and carried out the rutting experiments to calculate the rut depth which verified the effectiveness of the method. Chen et al. [6] transformed the Burgers model to Prony series and used finite element software to calculate the creep compliance parameters and compared the results with Maxwell model. Behzadfar and Hatzikiriakos [7] studied the viscoelastic properties of bitumen via rheological testing, where they proposed their rheological constitutive models as well.

For general finite element analyze software such as ANSYS or ABAQUS, in which, the commonest way of setting the parameters of viscoelastic materials is entering the parameters as a Prony series $[8,9]$, describing the shear relaxation modulus thereof. However, they are inconsistent with 
parametric forms of the viscoelastic model. Saboo and Kumar [10] investigated the strain creep response of varying asphalt binders via four-element Burgers model under different temperature and stress amplitudes. The data of uniaxial creep tests with nonlinear least squares method was applied to fit the creep compliance at different temperatures. Compared with the Burgers model, the modified Burgers model can better explain the long-term deformation characteristics of asphalt mixtures more properly. Scholars have extensively studied the transformations and methods behind the Prony series version of the shear modulus based on the Burgers model $[11,12]$, while surprisingly the transformation method of the modified Burgers model has not yet been reported. Therefore, exploring the conversion method of the Prony series of the modified Burgers model is of greater theoretical and practical significance as it can better analyze the viscoelasticity of asphalt mixtures by using developed finite element analysis software, which has also motivated this research.

Different experimental methods had been applied to evaluate the creep performance of the asphalt concrete. Airey and Rahimzadeh [13] designed a special tension-compression apparatus to test the viscoelastic properties of the asphalt mixtures. Diaz [11] applied modified cyclic creep test to evaluate the creep performance of the cold mix asphalt. Yao et al. [14] utilized flexural beam test to present the dynamic modulus and flexural stiffness of different surfacing materials on steel bridge decks including gussasphalt, epoxy asphalt concrete, which exhibited the difference between the dynamic modulus and the flexural stiffness. Yan et al. [15] made use of bending beam rheometer to determine the time-varying temperature rheological properties of waste tire rubber and reclaimed low density polyethylene asphalt mixtures. In the monograph [16], Sun presented extensive finite element analysis and experimental data showing that a kind of direct penetration method can reflect the actual stress state of the pavement properly. The static strength parameters including the shear strength, friction angle, and cohesive strength are also deducted. Thus, the uniaxial penetration method should also be suitable to measure the creep performance of the gussasphalt mixture. Meanwhile, the new formulation of gussasphalt mixture and novel structural layer has been utilized in the construction of the 4th Nanjing Yangtze River Bridge which is 6th largest suspension bridge in the world [4]. However, the viscoelastic properties of the novel asphalt pavement have never been measured, which motivated the penetration experiments.

In this study, we devote to obtain the correct viscoelastic parameters of gussasphalt mixture via direct penetration method. First, the Prony series transformation method of the modified Burgers model is deduced and a simple numerical simulation is adopted to demonstrate the correctness of the proposed transformation equations. Then, to explore the viscoelastic properties of the gussasphalt, uniaxial penetration creep experiments under different temperatures are carried out. In the end, the stress-correction procedure to obtain the viscoelastic parameters is proposed and verified. The experimental data and simulation data are compared which shows the correctness of the method in this paper.

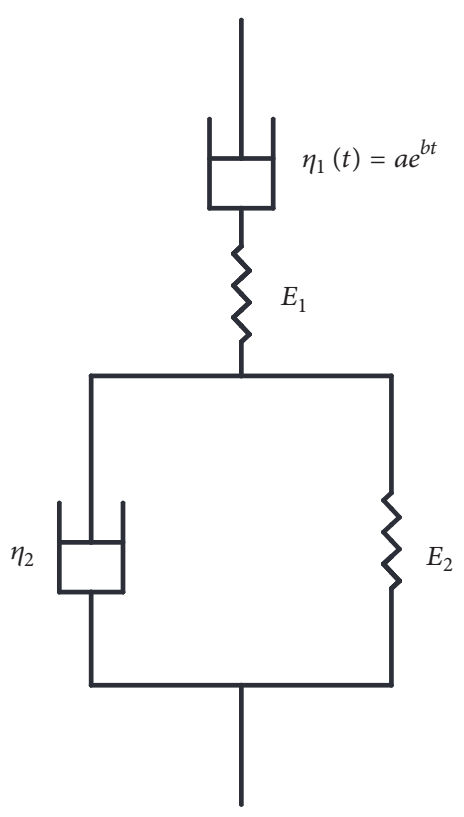

Figure 1: Modified Burgers model.

\section{The Explicit Prony Series Form of the Modified Burgers Model}

2.1. Prony Series Derivation of the Modified Burgers Model. Asphalt mixture is a kind of viscoelastic material, which exhibits creep properties under various loads, where the recoverable and nonrecoverable creeps of hardening mixture materials can be described by using Kelvin model and Maxwell model. The Burgers model is connected by the Kelvin model and the Maxwell model in series with four-unitfour-parameters to predict the creep behaviors of mixtures. Based on the model, $\mathrm{Xu}$ and $\mathrm{Zhu}$ [5], proposed a five-unitfour-parameters viscoelastic model, as shown in Figure 1, which is called the modified Burgers model.

Creep compliance is defined as the strain function changing with time under the effect of unit stress. According to the constitutive model in Figure 1, the creep compliance of the modified Burgers model is expressed as

$$
J(t)=\frac{1}{E_{1}}+\frac{1}{a b}\left(1-e^{-b t}\right)+\frac{1}{E_{2}}\left(1-e^{-\left(E_{2} / \eta_{2}\right) t}\right) .
$$

In general finite element analysis software, the Prony series of the shear relaxation modulus of relevant materials is generally input by defining the properties of nonlinear viscoelastic materials. The form of the Prony series used for the shear relaxation modulus is

$$
G(t)=G_{0}+G_{1}\left(\sum_{i}^{n} a_{i} e^{-t / t_{i}}\right)
$$

where $G_{1}, a_{i}$, and $t_{i}$ represent the initial shear modulus, the relative shear modulus, and the relaxation time, respectively.

In the expression of creep compliance equation (1), the five viscoelastic parameters cannot be directly accessed as the 
Prony series, while relevant viscoelastic parameters should be converted into the parameters relating to the Prony parameters of the shear relaxation modulus. (1):

The three-dimensional (3D) form is utilized to represent

$$
J(t)=\frac{1}{2}\left[\frac{1}{G_{1}}+\frac{1}{A B}\left(1-e^{-B t}\right)+\frac{1}{G_{2}}\left(1-e^{-\left(G_{2} / n_{2}\right) t}\right)\right],
$$

where $G_{1}$ and $G_{2}$ stand for the shear moduli corresponding to $E_{1}$ and $E_{2}$ and $n_{2}$ indicates the $3 \mathrm{D}$ viscosity coefficient corresponding to $\eta_{2}$. In addition, $A$ and $B$ corresponding to $a$ and $b$ represent the $3 \mathrm{D}$ parameters of the modified Burgers model.

When the viscoelastic volume deformation is not considered, the shear modulus shows the following relationships with the elastic modulus and the five coefficients are

$$
\begin{aligned}
G_{1} & =\frac{E_{1}}{2(1+\mu)}, \\
G_{2} & =\frac{E_{2}}{3}, \\
n_{2} & =\frac{\eta_{2}}{3}, \\
A & =\frac{a}{3}, \\
B & =b .
\end{aligned}
$$

Concerning the convolution relationship between the creep compliance $J(t)$ and the relaxation modulus $Y(t)$ of viscoelastic materials, it can be found that [12]

$$
\int_{0}^{t} J(\tau) Y(t-\tau) d \tau=\int_{0}^{t} J(\tau) Y(t-\tau) d \tau=t .
$$

The Laplace transformation is applied to both sides of (5), leading to

$$
\overline{J(s)} * \overline{Y(s)}=\frac{1}{s^{2}}
$$

where $\overline{J(s)}$ and $\overline{Y(s)}$ are Laplace transformation of $J(s)$ and $Y(s)$.

It can be seen, from the Laplace transformation of (3), that

$$
\overline{J(s)}=\frac{1}{2}\left[\frac{1}{G_{1} s}+\frac{1}{A s(s+B)}+\frac{1}{s\left(n_{2} s+G_{2}\right)}\right] .
$$
ulus is

Then, the Laplace transformation of the relaxation mod-

$$
\overline{Y(s)}=\frac{1}{\overline{J(s)} * s^{2}}=\frac{2}{s\left[\frac{1}{G_{1}}+\frac{1}{A(s+B)}+\frac{1}{n_{2} s+G_{2}}\right]}
$$

To prepare the system for inverse Laplace transformation, formula (8a) is rewritten as

$$
\overline{Y(s)}=2 *\left(\frac{q_{1}}{s}+\frac{q_{2}}{s+\alpha}+\frac{q_{3}}{s+\beta}\right),
$$

where the parameters are

$$
\begin{aligned}
\alpha, \beta & =-\frac{1}{2} *\left[-\frac{A\left(B n_{2}+G_{2}\right)+G_{1} n_{2}+G_{1} A}{A n_{2}} \pm \sqrt{\left.\left(\frac{A\left(B n_{2}+G_{2}\right)+G_{1} n_{2}+G_{1} A}{A n_{2}}\right)^{2}-4 * \frac{A B G_{2}+G_{1} G_{2}+G_{1} A B}{A n_{2}}\right],}\right. \\
q_{1} & =\frac{A B G_{1} G_{2}}{A B G_{2}+G_{1} G_{2}+G_{1} A B}, \\
q_{2} & =\frac{N-\alpha M}{\beta-\alpha} \\
q_{3} & =\frac{\beta M-N}{\beta-\alpha}
\end{aligned}
$$

and the inner parameters $M$ and $N$ are

$$
\begin{aligned}
& M=q_{2}+q_{3}=\frac{G_{1}^{2}\left(A B+G_{2}\right)}{A B\left(G_{1}+G_{2}\right)+G_{1} G_{2}}, \\
& N=q_{2} \beta+q_{3} \alpha=\frac{\left(A B^{2} n_{2}+G_{2}^{2}\right) G_{1}^{2}}{n_{2}\left[A B\left(G_{1}+G_{2}\right)+G_{1} G_{2}\right]} .
\end{aligned}
$$

An inverse Laplace transformation is performed to the both sides of $(8 b)$, which states that

$$
Y(t)=2 *\left(q_{1}+q_{2} e^{-\alpha t}+q_{3} e^{-\beta t}\right) .
$$

Then the shear modulus $G(t)$ can be obtained:

$$
G(t)=\frac{1}{2} Y(t)=q_{1}+q_{2} e^{-\alpha t}+q_{3} e^{-\beta t} .
$$




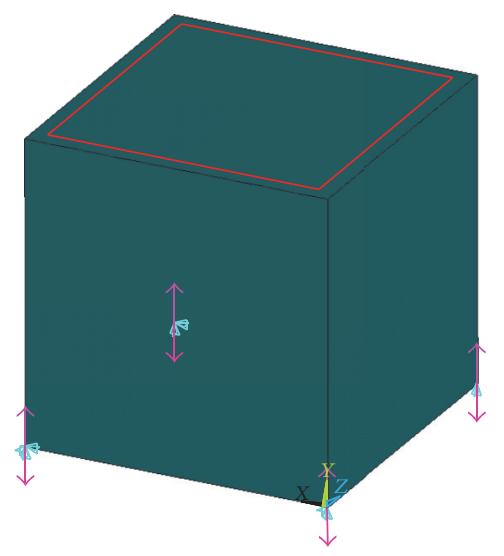

FIgURE 2: Schematic diagram of the ANSYS model.

In this way, the parameters of Prony series of materials require to be input to the chosen finite element software as

$$
\begin{aligned}
& a_{1}=\frac{q_{2}}{G_{1}}, \\
& t_{1}=\frac{1}{\alpha}, \\
& a_{2}=\frac{q_{3}}{G_{1}}, \\
& t_{2}=\frac{1}{\beta} .
\end{aligned}
$$

From (13), the explicit parameters for Prony series of the modified Burgers model are obtained, which can be utilized directly to the finite element soft suites such as ANSYS.

2.2. Verification of Prony Series Transformation Equation. To verify the correctness of the derived results of the Prony series of the modified Burgers model, this study establishes the ANSYS finite element model, as shown in Figure 2. The SOLID185 element with the size being $1 \mathrm{~mm} * 1 \mathrm{~mm} * 1 \mathrm{~mm}$ is used, and there is totally 1 element with 8 nodes. The material properties are taken from the properties of the Modified Burgers model in Table 1. The boundary conditions are shown in Figure 2, and the uniform load of 0.7 MPa is applied to the top surface of the element.

The nodal strain data of the nodes obtained by the ANSYS simulation are transformed into the creep compliance and compared with the theoretical calculation results of the modified Burgers model, as demonstrated in Table 2. It can be found that the finite element simulation results are consistent with the theoretical calculation results, and the relative error is less than $0.70 \%$. So the simulation results show that the Prony series results are reliable. By employing this method, the material parameters of the viscoelastic material can be accurately entered to the finite element software. However, the numerical simulation unit force is uniform, which has difference with the actual creep penetration experiments.

\section{Penetration Experiments and Verification}

3.1. Penetration Test Schemes of the Asphalt Mixture. To obtain the viscoelastic parameters of the practical gussasphalt mixture, the uniaxial penetration experiments, which had been practically proved effective to evaluate the shear resistance of the asphalt mixture by Sun [16], was conducted. The uniaxial penetration tests in this study are performed on rutting specimens (the gradation composition is shown in Table 3) with the dimension of $30 \mathrm{~cm} \times 28 \mathrm{~cm} \times 5 \mathrm{~cm}$. To avoid size effection of the coarse aggregates, the dimension of the pressure head is chosen as $100 \mathrm{~mm}$ which is about 3 times larger than the largest coarse aggregate in the gussasphalt.

In these experiments, an instantaneous load is applied on the center of the specimen and kept unchanged, during which the time-varying displacement of the pressure head was measured, which can be utilized to obtain the timely strain of the specimen. The only measurement in the experiment is the displacement of the pressure head. The constant pressure is controlled by the material test system and the exampling frequency is $30 \mathrm{~Hz}$. The whole process of the uniaxial penetration creep experiment is simple and very easy to apply, which is an obvious advantage of the uniaxial penetration method.

WANCE material test system is employed in the tests, equipped with the pressure head to apply a constant pressure of $0.7 \mathrm{MPa}$ for 3600 seconds at constant temperatures of $40^{\circ} \mathrm{C}, 50^{\circ} \mathrm{C}$, and $60^{\circ} \mathrm{C}$, respectively. To keep the specimens working in constant temperatures, a water tank controlled by a constant temperature bath is applied, shown in Figure 3(a). Figure 3(a) also shows the whole configuration of the penetration experiments and Figure 3(b) presents a specimen after the experiment.

3.2. Procedure to Obtain Viscoelastic Parameters via Experimental Data and Finite Element Method. To fit the compliance curve of the gussasphalt, the stress as well as the strain should be known. In the finite element simulation mentioned above, the stress of the specimen is assumed to be uniform and known. However, in the actual experiments, the stress status of the gussasphalt is unknown. Thus, after obtaining the measured data from the experiments, to find the proper viscoelastic parameters of the gussasphalt mixtures, three steps are essential in this paper.

Firstly, we assume that the vertical stress in the asphalt mixture is constant and equals the pressure applied by the head, which is $0.7 \mathrm{MPa}$. Based on the assumption, the creep compliance curve is fitted by utilizing the modified Burgers model, and each parameter in the model can be calculated by using Matlab via (12) and (13). The initial fitting results and the Prony series are listed in Table 4 by assuming Poisson's ratio of the mixture 0.25 , which are regarded as the initial parameters.

Secondly, using the initial material parameters in Table 4, the finite element model of the uniaxial penetration creep test is established where the ANSYS element SOLID 185 is adopted, as shown in Figure 4. The circular loading area is located in the center of the model with a diameter of $10 \mathrm{~cm}$ and a transitional zone between the loading areas. The 
TABLE 1: Material properties of the calculation example.

\begin{tabular}{lcccccccc}
\hline & \multicolumn{3}{c}{ Parameters of modified Burgers model } & \multicolumn{4}{c}{ Parameters of Prony series (shear modulus) } \\
$E_{1}(\mathrm{MPa})$ & $E_{2}(\mathrm{MPa})$ & $\eta_{2}(\mathrm{Mpa} * \mathrm{~s})$ & $a(\mathrm{Mpa} * \mathrm{~s})$ & $b(/ \mathrm{s})$ & $a_{1}$ & $t_{1}$ & $a_{2}$ \\
\hline 87.04 & 20.87 & $5.70 \times 10^{4}$ & $1.44 \times 10^{4}$ & $5.04 \times 10^{-3}$ & 0.2065 & 980.9978 & 0.6592 & 74.1388 \\
\hline
\end{tabular}

TABLE 2: The comparison between equation calculation results and the ANSYS simulation.

\begin{tabular}{lcccc}
\hline Time (s) & $\begin{array}{c}\text { Creep compliance of equation } \\
\text { calculation }\left(\mathrm{MPa}^{-1}\right)\end{array}$ & Strain of ANSYS & $\begin{array}{c}\text { Creep compliance of } \\
\text { ANSYS }\left(\mathrm{MPa}^{-1}\right)\end{array}$ & $\begin{array}{c}\text { Relative error }(\%) \\
1\end{array}$ \\
\hline $1.16 E-02$ & $8.07 E-03$ & $1.15 E-02$ & -0.37 \\
101 & $1.87 E-02$ & $1.32 E-02$ & $2.88 E-02$ & 0.50 \\
201 & $2.37 E-02$ & $1.67 E-02$ & $2.74 E-02$ & 0.67 \\
301 & $2.72 E-02$ & $1.92 E-02$ & $3.43 E-02$ & 0.69 \\
601 & $3.41 E-02$ & $2.40 E-02$ & $3.88 E-02$ & 0.60 \\
901 & $3.86 E-02$ & $2.72 E-02$ & $4.86 E-02$ & 0.54 \\
1801 & $4.84 E-02$ & $3.40 E-02$ & $5.56 E-02$ & 0.36 \\
2701 & $5.54 E-02$ & $3.89 E-02$ & $6.05 E-02$ & 0.30 \\
3601 & $6.04 E-02$ & $4.24 E-02$ & \\
\hline
\end{tabular}

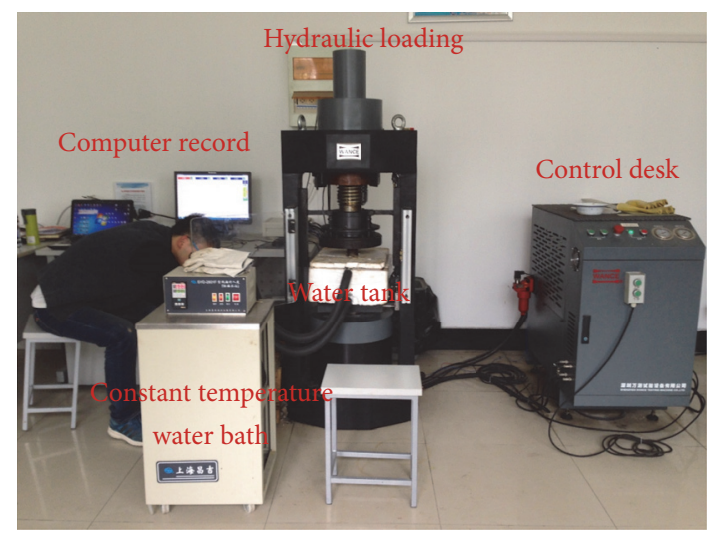

(a) Test equipment

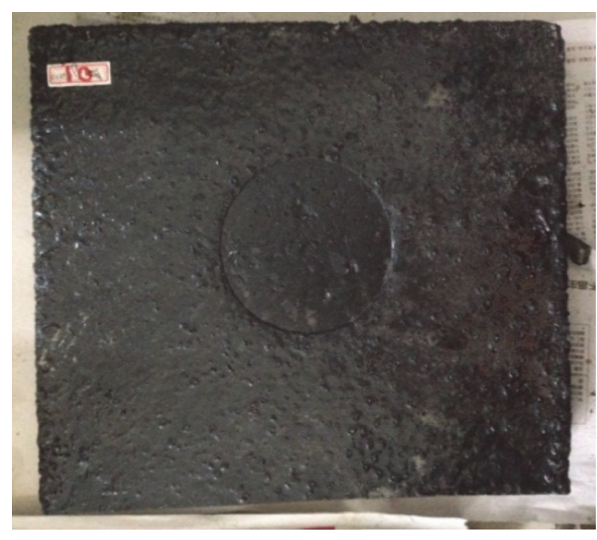

(b) The asphalt rutting specimens

FIGURE 3: Uniaxial penetration tests on the asphalt rutting board.

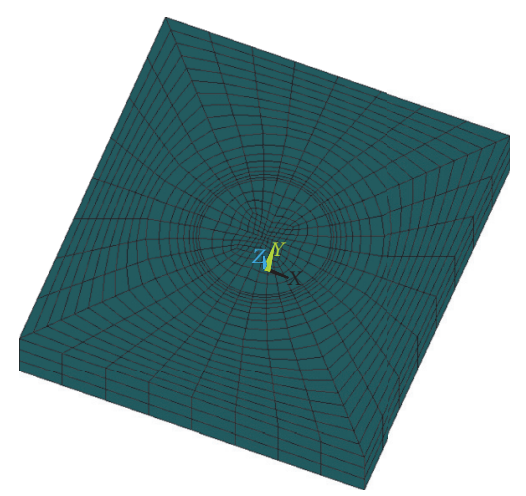

FIGURE 4: The model of uniaxial penetration creep test finite element. 


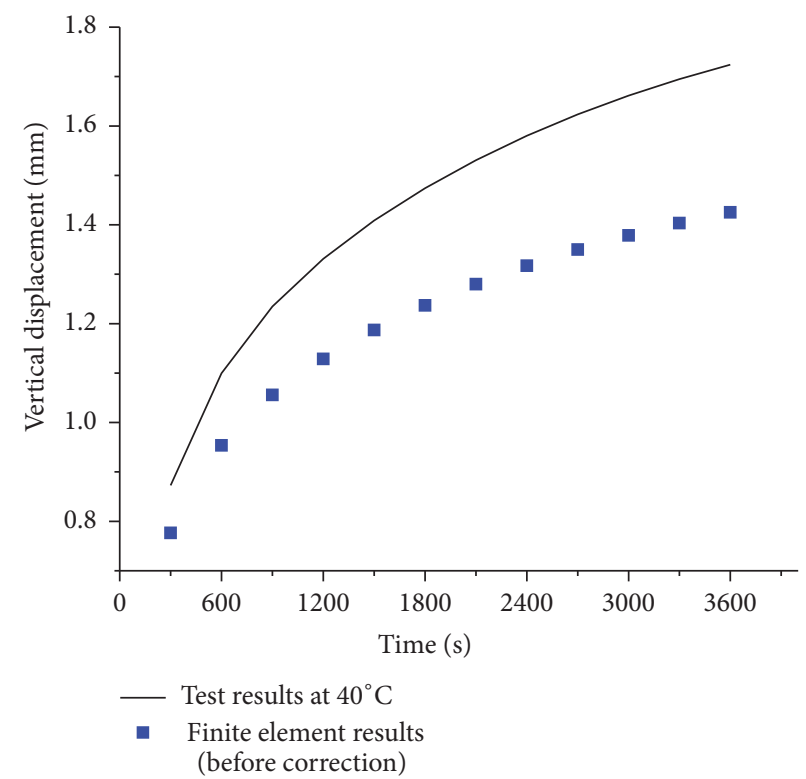

FIGURE 5: Comparison between the finite element results and the experimental results before correction $\left(40^{\circ} \mathrm{C}\right)$.
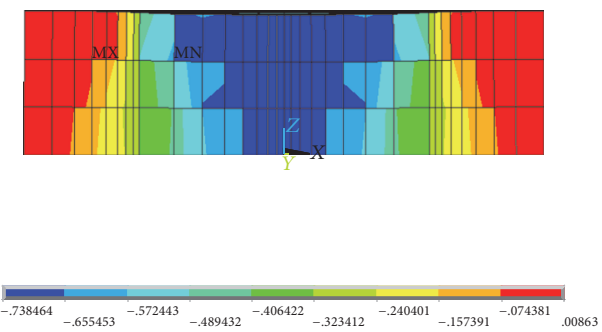

FIGURE 6: Vertical stress cloud of central section.

TABLE 3: Gradation composition of the asphalt mixture.

\begin{tabular}{|c|c|c|}
\hline \multicolumn{2}{|c|}{ Component } & $\begin{array}{c}\text { Grading/asphalt } \\
\text { content }\end{array}$ \\
\hline \multirow{4}{*}{$\begin{array}{l}\text { Mineral aggregate } \\
\text { (basalt) }\end{array}$} & 2\# $(4.75 \sim 9.5 \mathrm{~mm})$ & 27 \\
\hline & $3 \#(2.36 \sim 4.75 \mathrm{~mm})$ & 23 \\
\hline & Natural sand & 24 \\
\hline & Mineral dust & 26 \\
\hline \multicolumn{2}{|c|}{ High elastic modified bitumen } & $8.3 \%$ \\
\hline
\end{tabular}

model boundary is $18 \mathrm{~cm}$. The boundary conditions include the vertically constrained bottom surface and the bottom with four corners fixed in three directions. A constant load of $0.7 \mathrm{MPa}$ is applied to the central circular loading area. The calculation results under temperature $40^{\circ} \mathrm{C}$ are shown in Figure 5 as an example.

Figure 5 clearly shows that the simulation results and experimental results are far from matching. This phenomenon is predictable because the inner vertical stress of the rutting plate is not the same value applied by the pressure head. By analyzing the vertical stress of the test example, Figures 6 and 7 show the contour of the vertical stress inside the plate. We can find that the vertical stress inside the asphalt material changes along the height of the specimen. If we take the average vertical stress ( $Z$ direction) of the asphalt cylinder under the pressure head as the representative value (the vertical stress points are chosen as illustrated in Figure 7 and the stress points under the pressure head line along the dimension due to the symmetry), it is significantly smaller than the value applied by the pressure head in the tests. Meanwhile, although the mean value of the vertical principal stress varies with time, as shown in Figure 8, the changing amplitude is tiny and less than $0.1 \%$ of the vertical stress during the test time. Thus, the average vertical stress of the gussasphalt mixture under the pressure head in the end time of the experiment can be approximately taken as the mean vertical stress of the specimen along the height, which is $0.5929 \mathrm{Mpa}$ in this example. It is much smaller and more precise than the initial pressure $0.7 \mathrm{MPa}$ to calculate the creep compliance curve. Here a new parameter $\alpha$ is introduced to update the model parameters of the modified Burgers model.

$$
\alpha=\left(\frac{p_{2}}{p_{1}}\right),
$$

where $p_{1}$ is the pressure stress before updating and $p_{2}$ is the updated stress. If the parameter $\alpha$ equals 1 or $|\alpha-1|<\varepsilon$ (where $\varepsilon$ is a small value) then we can conclude that the results have 
TABLE 4: Fitting results of experimental data.

\begin{tabular}{lccccccccc}
\hline \multirow{2}{*}{ Temperature } & \multicolumn{4}{c}{ Parameters of modified Burgers model } & \multicolumn{4}{c}{ Parameters of Prony series (shear modulus) } \\
& $E_{1}(\mathrm{MPa})$ & $E_{2}(\mathrm{MPa})$ & $\eta_{2}(\mathrm{Mpa} * \mathrm{~s})$ & $a(\mathrm{Mpa} * \mathrm{~s})$ & $b(/ \mathrm{s})$ & $a_{1}$ & $t_{1}$ & $a_{2}$ & $t_{2}$ \\
\hline 40 & 88.34 & 34.85 & $8.03 E+04$ & $1.81 E+04$ & $3.62 E-03$ & 0.1432 & 1167.1852 & 0.6801 & 96.3290 \\
50 & 72.02 & 25.95 & $5.94 E+04$ & $1.28 E+04$ & $5.47 E-03$ & 0.2107 & 984.6694 & 0.6095 & 76.4215 \\
60 & 58.92 & 21.22 & $4.53 E+04$ & $9.66 E+03$ & $5.47 E-03$ & 0.1933 & 947.9533 & 0.6303 & 72.6607 \\
\hline
\end{tabular}

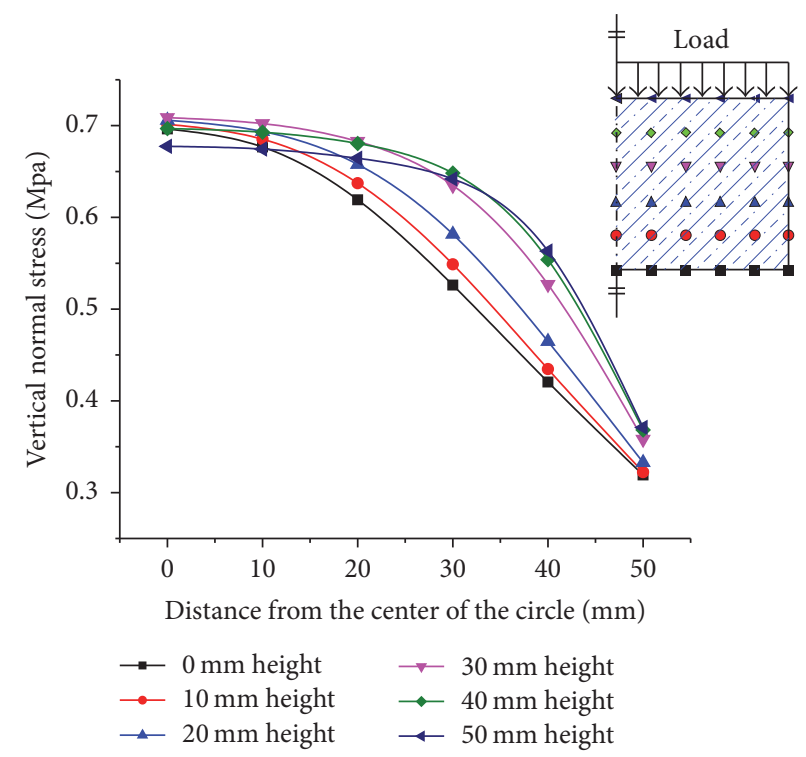

FIGURE 7: Distribution of vertical stress under the loading area.

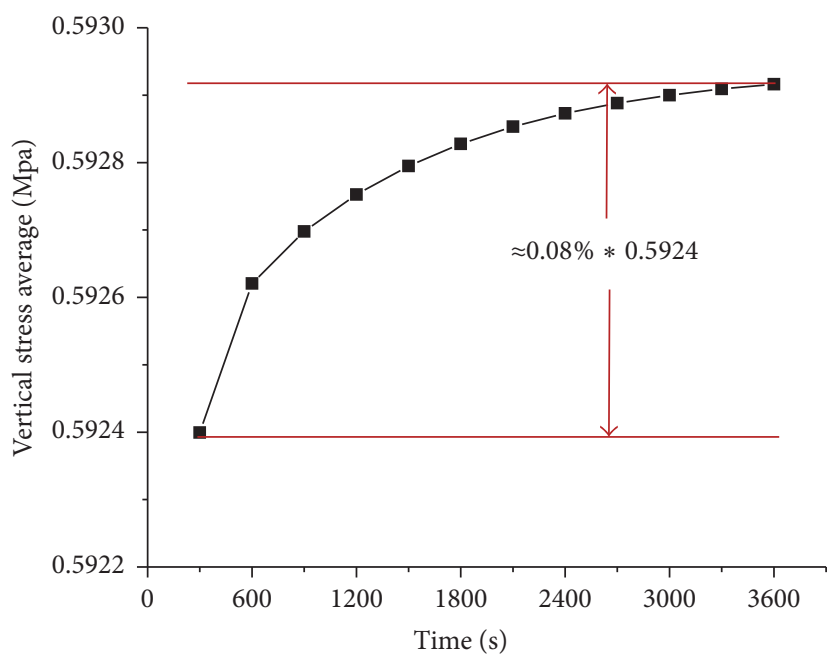

FIgURE 8: Time history of mean values of the vertical stress.

converged. Using the definition, the correction coefficient $\alpha$ in current example can be calculated (where $\alpha$ is $0.7 / 0.5929$ $=1.18$ ). Then by turning the creep compliance $J(t)$ into $\alpha J(t)$ and refit the curve, the updated material parameters can be achieved, as shown in Table 5.

Thirdly, the updated material parameters are utilized to resimulate the experiment. The results before and after correction as well as the relative errors are shown in Figures 9 and 10. The same procedure can be applied to the experimental specimens under temperature $50^{\circ} \mathrm{C}$ and $60^{\circ} \mathrm{C}$. Figure 9 demonstrates the displacements measured in the penetration experiments as well as predicted results before and after stress correction by finite element analysis under different temperatures. Figure 10 shows the comparison of the relative errors between the simulated and experimental results before and after stress correction. From the comparison of 


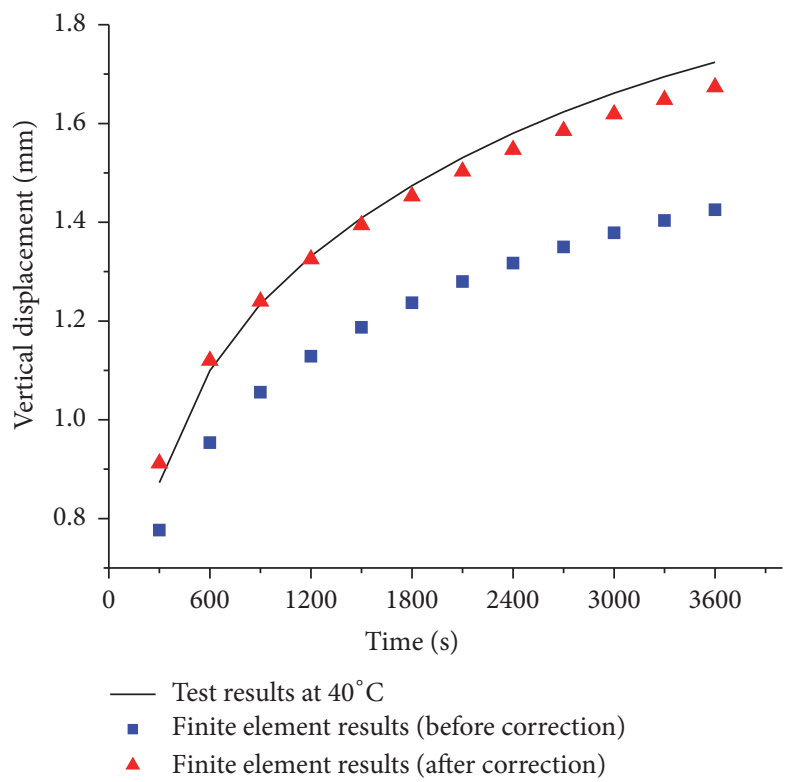

(a)

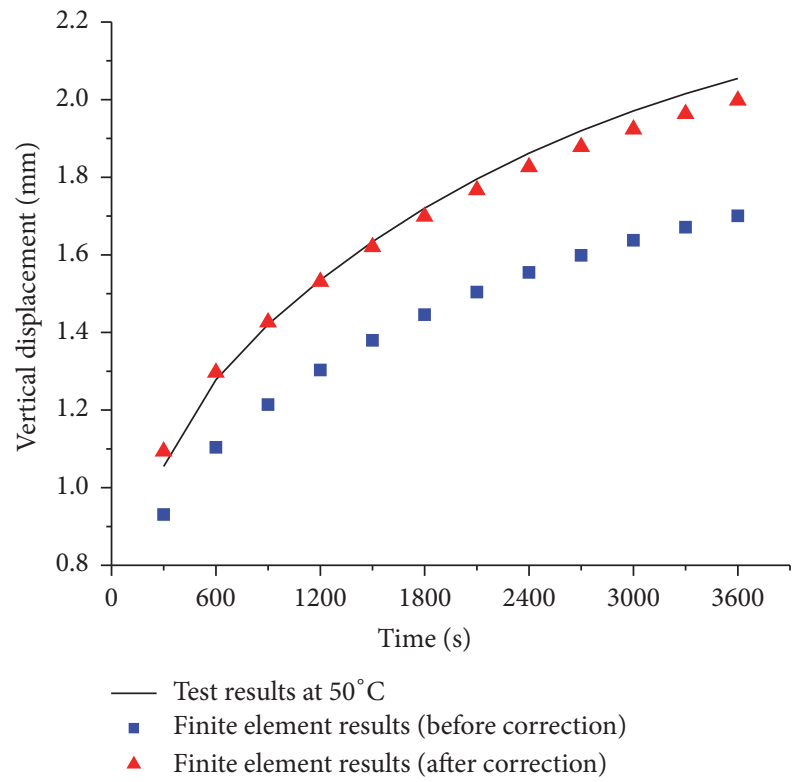

(b)

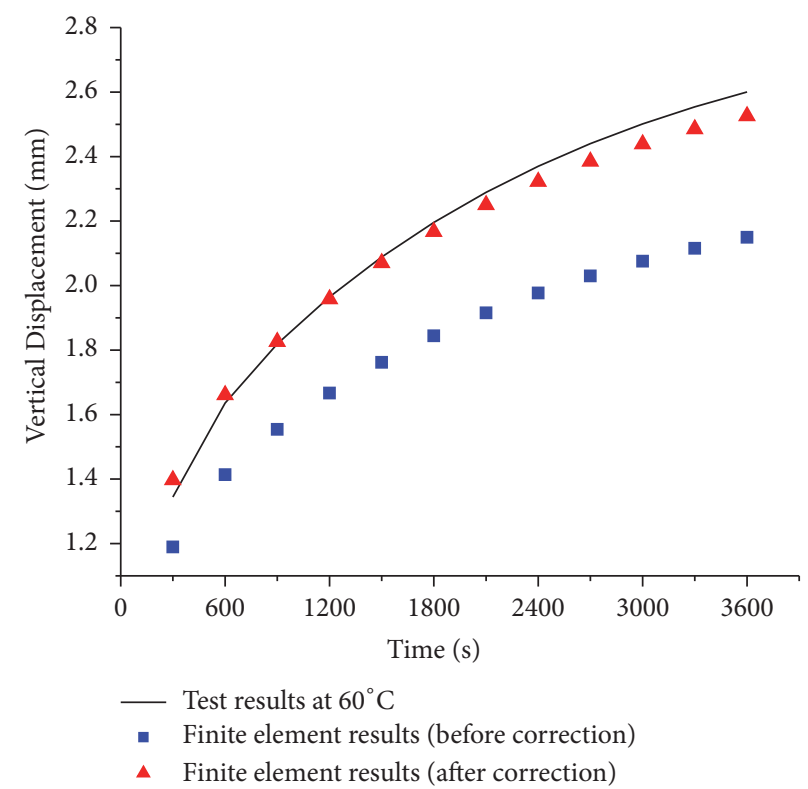

(c)

FiguRE 9: Comparison between the finite element results and the experimental results before and after correction at $40^{\circ} \mathrm{C}(\mathrm{a}), 50^{\circ} \mathrm{C}(\mathrm{b})$, or $60^{\circ} \mathrm{C}(\mathrm{c})$.

TABLE 5: Experimental data fitting results after stress correction.

\begin{tabular}{|c|c|c|c|c|c|c|c|c|c|c|c|}
\hline \multirow{2}{*}{ Temperature } & \multicolumn{5}{|c|}{ Parameters of modified Burgers model } & \multicolumn{4}{|c|}{$\begin{array}{l}\text { Parameters of Prony series } \\
\quad \text { (shear modulus) }\end{array}$} & \multirow{2}{*}{$\begin{array}{c}\text { Stress } \\
\text { correction } \alpha\end{array}$} & \multirow{2}{*}{$\begin{array}{l}\text { Iteration } \\
\text { number }\end{array}$} \\
\hline & $E_{1}(\mathrm{MPa})$ & $\begin{array}{c}E_{2} \\
(\mathrm{MPa})\end{array}$ & $\eta_{2}(\mathrm{Mpa} * \mathrm{~s})$ & $a(\mathrm{Mpa} * \mathrm{~s})$ & $b(/ \mathrm{s})$ & $a_{1}$ & $t_{1}$ & $a_{2}$ & $t_{2}$ & & \\
\hline 40 & 74.83 & 29.52 & $6.80 E+04$ & $1.53 E+04$ & $3.62 E-03$ & 0.1432 & 1167.1852 & 0.6801 & 96.3290 & 1.18 & 1 \\
\hline 50 & 61.00 & 21.98 & $5.03 E+04$ & $1.08 E+04$ & $5.47 E-03$ & 0.2107 & 984.6694 & 0.6095 & 76.4215 & 1.18 & 1 \\
\hline 60 & 49.91 & 17.97 & $3.84 E+04$ & $8.18 E+03$ & $5.47 E-03$ & 0.1933 & 947.9533 & 0.6303 & 72.6607 & 1.18 & 1 \\
\hline
\end{tabular}




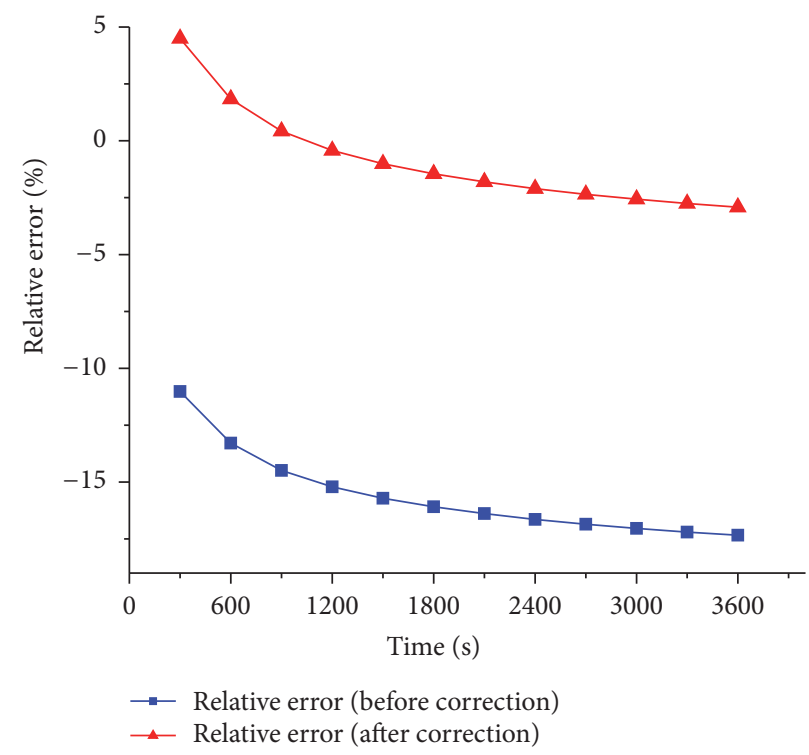

(a)

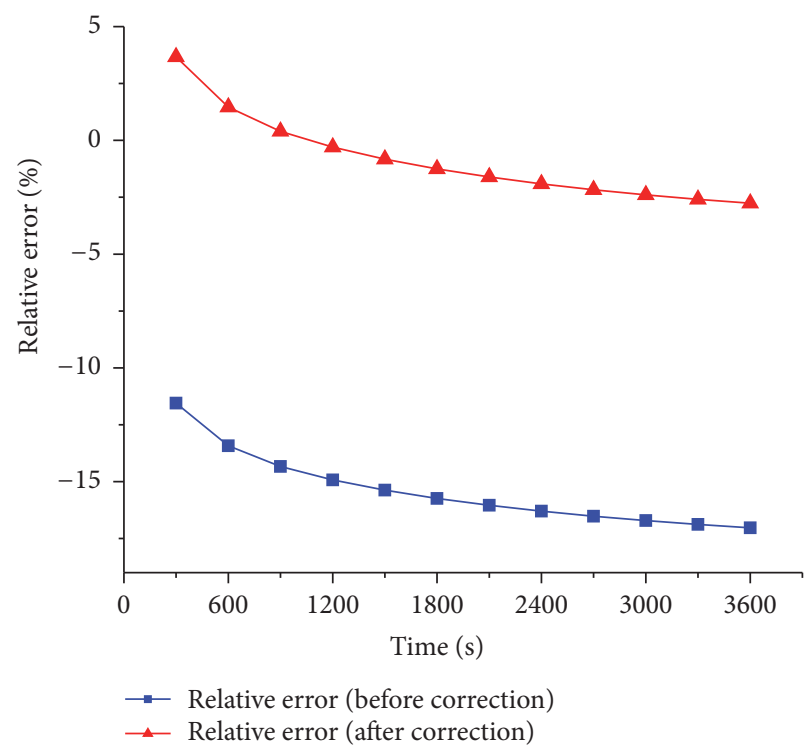

(b)

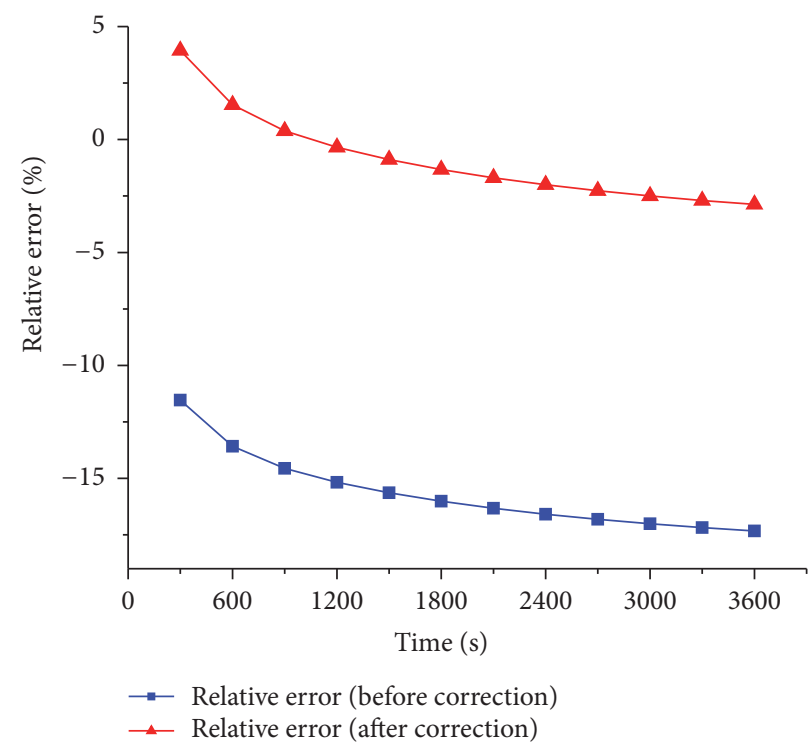

(c)

FIGURE 10: Comparison of relative error before and after correction at $40^{\circ} \mathrm{C}(\mathrm{a}), 50^{\circ} \mathrm{C}$ (b), or $60^{\circ} \mathrm{C}$ (c).

these figures, it can be clearly seen that the accuracy of finite element simulation of the penetration tests at different temperatures is greatly improved after the introduction of the correction coefficient. The maximum error of the finite element simulation is about $5 \%$ comparing with the experimental results. More iterations by following the procedure in Figure 11 can still be implemented to obtain more precise results if necessary. Then the rheological parameters of the gussasphalt mixtures can be obtained successfully.

\section{Conclusion}

In this paper, to obtain the viscoelastic parameters of gussasphalt mixtures, the explicit parameters of modified Burgers model based on Prony series are derived and the uniaxial penetration creep experiments of gussasphalt mixture are carried out. The parameter identification procedure by stress correcting is proposed to find accurate model parameters of gussasphalt mixture and the effectiveness of the method is validated by FEM simulation and experimental data.

Based on the work, the following conclusions can be drawn:

(1) The explicit form Prony series of the modified Burgers model is obtained. The viscoelastic properties of gussasphalt mixtures can be easily input into the commercial finite element software to explore the nonlinear properties. The correctness of the transformation equations of the modified Burgers model is verified by the finite element model. 


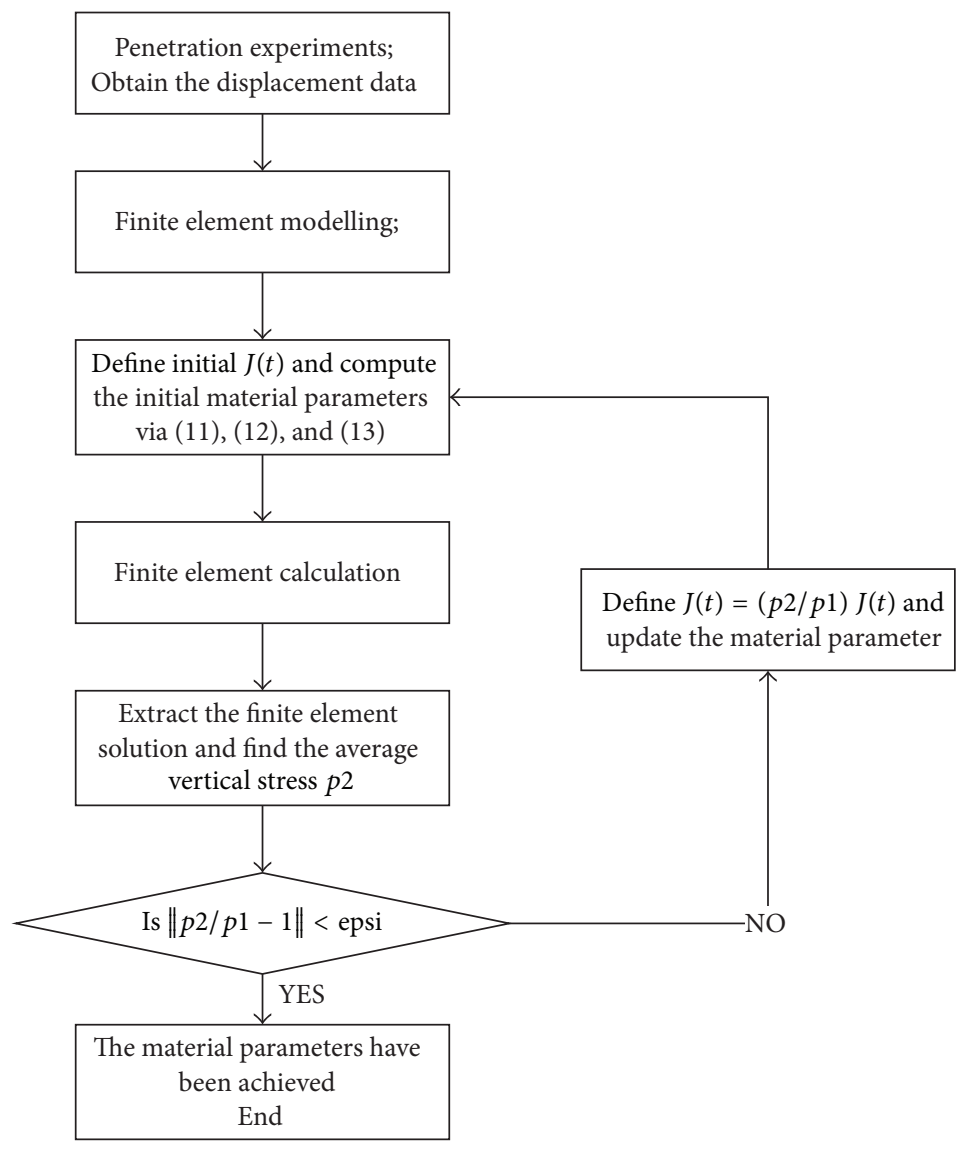

FIGURE 11: Flow chart of stress-correction method.

(2) The viscoelastic parameter identification procedure combined with the stress-correcting method of the gussasphalt mixture based on uniaxial penetration creep experiment under different temperatures is carried out. After stress correcting, the experimental data can be well simulated by FEM software, following the presented procedure.

(3) The penetration experiment can imitate the stress status of the pavement and is relatively easy to realize. The method combined with the Prony series via the modified Burgers model as well as stress-correcting iteration proposed in this paper can be extended to other materials with viscoelastic properties.

\section{Competing Interests}

The authors declare that there is no conflict of interests.

\section{Acknowledgments}

The work was supported by the general programs of the National Natural Science Foundation of China (51478163); the youth projects of the Natural Science Foundation of Jiangsu Province, China (BK2012412); the Fundamental Research Funds for the Central Universities of China under the Grant of 2015B17614; and partial support of Zhejiang Transportation Scientific Research under the Grant of 2014W01; 2014 H27.

\section{References}

[1] D. Lesueur, J.-F. Gerard, P. Claudy, J.-M. Letoffe, J.-P. Planche, and D. Martin, "A structure-related model to describe asphalt linear viscoelasticity," Journal of Rheology, vol. 40, no. 5, pp. 813836, 1996.

[2] M. O. Marasteanu, T. Clyne, J. McGraw, X. Li, and R. Velasquez, "High-temperature rheological properties of asphalt binders," Journal of the Transportation Research Board, vol. 1901, pp. 5259, 2005.

[3] R. Jones, D. Horner, P. Sullivan, and R. Ahlvin, "A methodology for quantitatively assessing vehicular rutting on terrains," Journal of Terramechanics, vol. 42, no. 3-4, pp. 245-257, 2005.

[4] D. J. Zhang, "Design of the composite gussasphalt steel pavement of the large span steel box girder," Journal of Chongqing University (Nature Science), vol. 34, no. 05, pp. 5-13, 2015.

[5] S. F. Xu and Z. H. Zhu, "Prediction of rutting of asphalt pavement by viscoelastic theory," Journal of Tongji University, vol. 18, no. 3, pp. 299-305, 1990.

[6] J. Chen, C. Zhou, and Z. Wang, "Data processing and viscoelastic computation for creep test of asphalt mixture," Journal of Southeast University, vol. 37, no. 6, pp. 1091-1095, 2007.

[7] E. Behzadfar and S. G. Hatzikiriakos, "Viscoelastic properties and constitutive modelling of bitumen," Fuel, vol. 108, pp. 391399, 2013.

[8] ANSYS Inc, Theory Manual of ANSYS, Version 11, SAS IP INC, 2015. 
[9] ABAQUS, Abaqus Analysis User's Guide, Version 6.14, Dassault Systems, 2015.

[10] N. Saboo and P. Kumar, "A study on creep and recovery behavior of asphalt binders," Construction and Building Materials, vol. 96, pp. 632-640, 2015.

[11] L. G. Diaz, "Creep performance evaluation of Cold Mix Asphalt patching mixes," International Journal of Pavement Research and Technology, vol. 9, no. 2, pp. 149-158, 2016.

[12] F. Mainardi and G. Spada, "Creep, relaxation and viscosity properties for basic fractional models in rheology," European Physical Journal: Special Topics, vol. 193, no. 1, pp. 133-160, 2011.

[13] G. D. Airey and B. Rahimzadeh, "Combined bituminous binder and mixture linear rheological properties," Construction and Building Materials, vol. 18, no. 7, pp. 535-548, 2004.

[14] B. Yao, G. Cheng, X. Wang, and C. Cheng, "Characterization of the stiffness of asphalt surfacing materials on orthotropic steel bridge decks using dynamic modulus test and flexural beam test," Construction and Building Materials, vol. 44, pp. 200-206, 2013.

[15] K. Yan, H. Xu, and L. You, "Rheological properties of asphalts modified by waste tire rubber and reclaimed low density polyethylene," Construction and Building Materials, vol. 83, pp. 143149, 2015.

[16] L. Sun, Structural Behavior of Asphalt Pavements: Integrated Analysis and Design of Conventional and Heavy Duty Asphalt Pavement, Butterworth-Heinemann, 1st edition, 2016. 

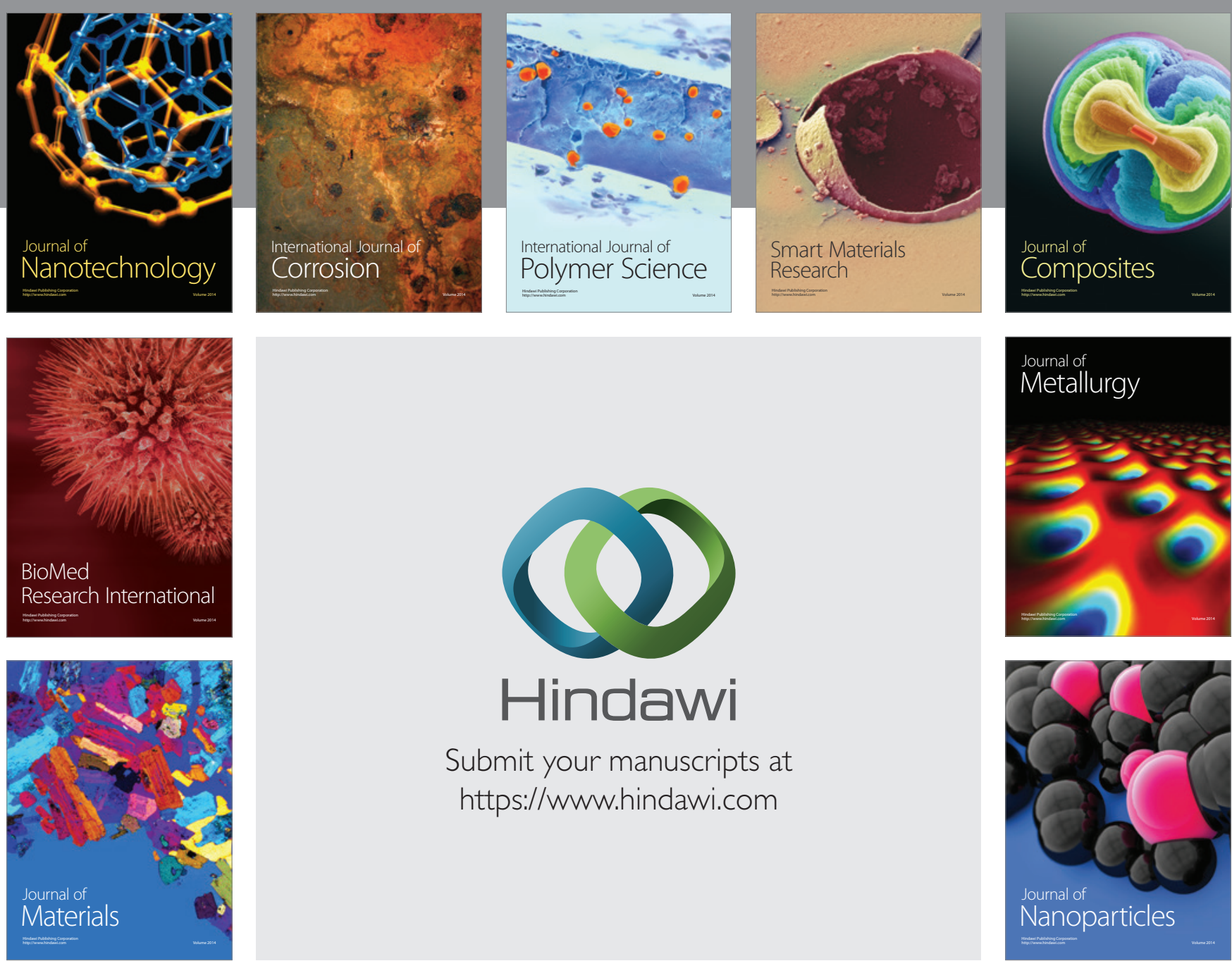

\section{Hindawi}

Submit your manuscripts at

https://www.hindawi.com

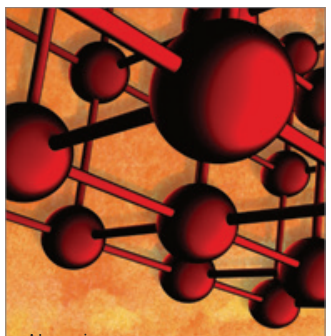

Materials Science and Engineering
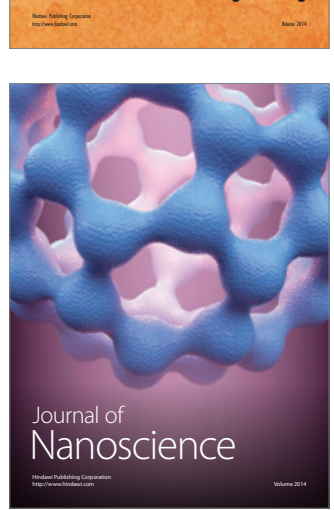
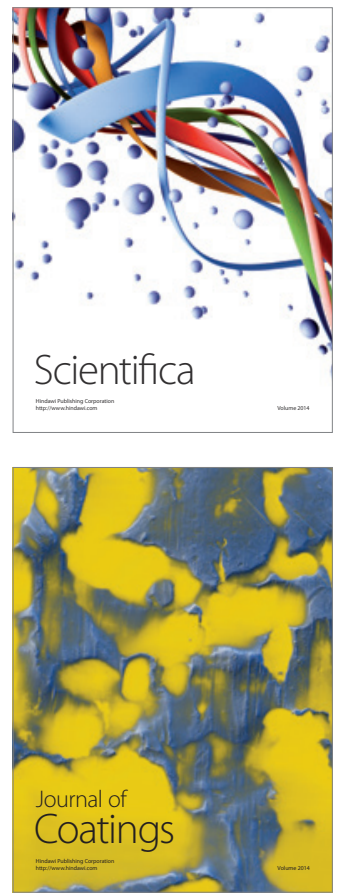
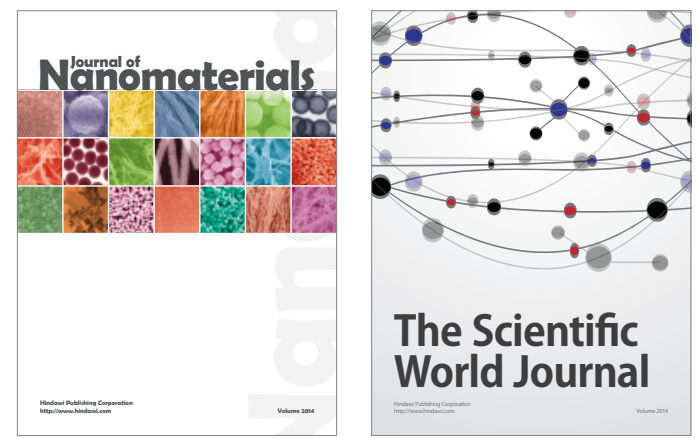

The Scientific World Journal
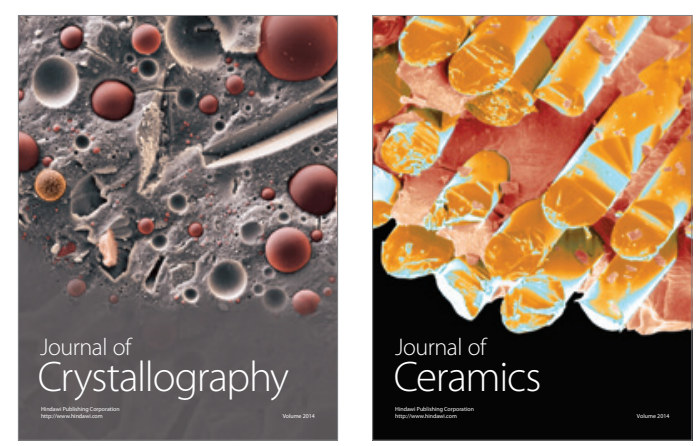
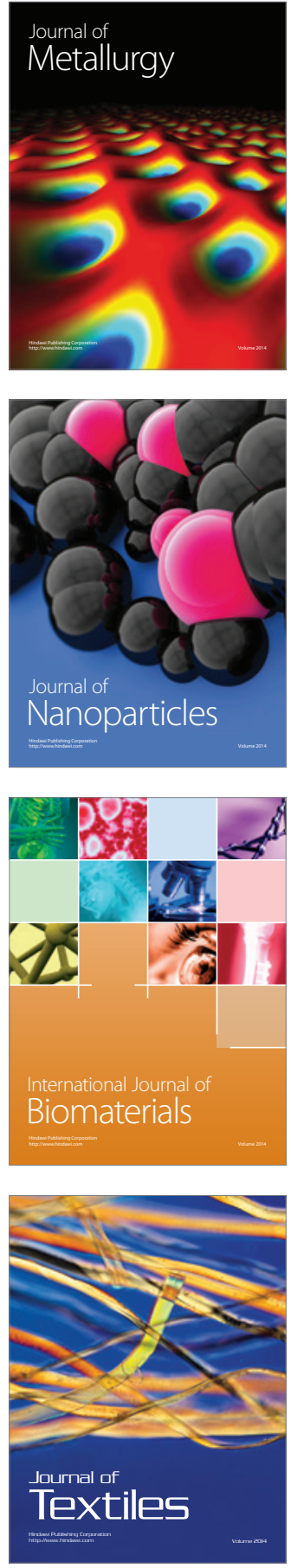